Boise State University

ScholarWorks

Marketing Faculty Publications and

Presentations

Department of Marketing

$11-2019$

\title{
It's About Our Values: How Founder's Stories Influence Brand Authenticity
}

Anne Hamby

Boise State University

David Brinberg

Virgina Tech

Kim Daniloski

Virginia Tech

This is the peer reviewed version of the following article: Hamby, A.; Brinberg, D.; \& Daniloski, K. (2019). It's About Our Values: How Founder's Stories Influence Brand Authenticity. Psychology \& Marketing, 36(11), 1014-1026.

which has been published in final form at doi: 10.1002/mar.21252. This article may be used for non-commercial purposes in accordance with Wiley Terms and Conditions for Self-Archiving. 
This is an author-produced, peer-reviewed version of this article. The final, definitive version of this document can be found online at Psychology \& Marketing, published by Wiley Periodicals, Inc.. Copyright restrictions may apply. doi: 10.1002/mar.21252

\title{
It's About Our Values: How Founder's Stories Influence Brand Authenticity
}

\author{
Anne Hamby \\ Boise State University
}

\author{
David Brinberg \\ Virginia Tech
}

\author{
Kim Daniloski \\ Virginia Tech
}

\begin{abstract}
Companies increasingly share the stories behind their brand's founding to engage consumers. The current studies explore how the motives that underlie business formation in founder's stories influence consumer brand perceptions. Specifically, stories that highlight self-transcendence (versus self-enhancement) founder values enhance the perceived authenticity of the focal brand. We examine narrative fidelity (Fisher, 1984) as a mechanism of narrative persuasion through which the audience judges whether the motives underlying character actions represent "good reasons" for action. Across three studies, we show that the values underlying a founder's motivation to start a business influence the perceived authenticity of the associated brand, and this relationship is mediated by narrative fidelity. Further, reader's personal values moderate the influence of founder's values on narrative fidelity judgments, and the relationship between narrative fidelity and brand authenticity is attenuated by a merger between the original company and another company, demonstrating a boundary condition of the observed relationships.
\end{abstract}

Keywords: narrative, persuasion, authenticity, brand biography, attitudes, values

"While traveling in Argentina in 2006, TOMS Founder Blake Mycoskie witnessed the hardships faced by children growing up without shoes. Wanting to help, he created TOMS Shoes, a company to match every pair of shoes purchased with a new pair of shoes for a child in need."

- Summary of the TOMS story, excerpted from the TOMs corporate website

Research in the consumer and psychology literatures indicate messages in narrative format are uniquely suited to influence consumer beliefs because narrative processing suppresses counter-arguing and is enjoyed by consumers (van Laer et al., 2014). Consistent with this academic research, practitioners and popular business press (e.g., Carnoy, 2016) describe founder's stories, a specific type of marketing narrative, as the "perfect marketing tool," because of their effect on perceived brand authenticity and to managers who invest resources to differentiate their brand from competitors (Beverland, 2010). Perceptions of brand authenticity have been linked to values-in-action (Bex, Atkinson, \& Bench-Capon, 2014), and narratives about brand founders allow companies to describe the values and actions that reflect the brand's authenticity.

While brand stories as a promotional platform and authenticity as an attribute of brands are rising in importance to both consumers and firms, there is little systematic assessment of specific narrative elements and the underlying mechanisms that enhance authenticity. In the current work, we examine whether founder's motives are an important determinant of brand authenticity in the context of a brand narrative. We draw from the literature on authentic leadership to identify specific values which lead to perceived authenticity and from the communications literature to adapt the construct of fidelity (Fisher, 1984), a judgment of a character's motives to act, as a mechanism in narrative persuasion to explain the relationships between values and authenticity.

The current work contributes to the literature on narrative persuasion in consumer and advertising research by examining an element common to stories - character motives - as an antecedent to a specific persuasion-related outcome (i.e., brand authenticity) and incorporating a new mechanism - narrative fidelity - to explain the persuasive effect of narratives beyond the effect of transportation into the narrative (i.e., van Laer et al., 2014). We focus on the product attribute of brand authenticity rather than other persuasion-related outcomes such as attitude towards the brand 
This is an author-produced, peer-reviewed version of this article. The final, definitive version of this document can be found online at Psychology \& Marketing, published by Wiley Periodicals, Inc.. Copyright restrictions may apply. doi: 10.1002/mar.21252

because of this attribute's increasing importance to consumers (Cohn \& Wolfe, 2014). We also contribute to the growing literature on authenticity by demonstrating certain values, which are associated with authenticity in leadership, have a similar effect on the authenticity of brands.

\section{Conceptual Background}

\section{Brand Founder's Stories}

Narratives are a distinct form of communication that feature chronological and causally connected events, which include "actors with motives, an event sequence, and a setting that has physical, social, and temporal components" (Padgett \& Allen, 1997, p. 53). Narratives create feelings, meanings, and a virtual world where people may mentally relocate, or become transported (Bruner, 1990; Polkinghorne, 1988; Sarbin, 1986; Green \& Brock, 2000). People process narratives less critically (Adaval \& Wyer, 1998; Escalas, 2007) and evaluate narratives in terms of their coherence or verisimilitude. In contrast, when people process argument-based messages, they consider explicit, logical arguments, and engage in critical scrutiny and argument-focused elaboration (Petty \& Cacioppo, 1986).

Recent narrative persuasion research has examined narrative elements that enhance transportation, such as an emotionally engaging plot and easily imaginable scenes, as antecedents to persuasion (van Laer et al., 2014). Other elements of narratives, however, may influence narative-related beliefs in ways that do not necessarily affect story involvement (transportation). For example, narratives enable readers to view the goal-action-outcome causal sequence that illustrates a character's values-in-action (Bex, Atkinson, \& Bench-Capon, 2014). Research in discourse psychology has identified a character's motives for action as a critical element of narrative processing and comprehension: readers monitor what a character wants to achieve and why (Bower \& Morrow, 1990). Paharia et al.'s (2010) work on underdog stories, for example, illustrates that consumers respond favorably to stories depicting disadvantaged characters who achieves success through persistence. Paharia et al. (2010) labeled this type of narrative a brand biography, "an unfolding story that chronicles the brand's origins, life experiences, and evolution over time (p. 776)." Brand biographies are more than a description of facts about the brand (e.g., its country of origin or manufacture or the origins of its ingredients); they describe anecdotes to shape a coherent narrative about the brand. We extend Paharia's (2010) work in several ways. We assess whether the effect of founder's values on brand authenticity is present in narratives or has an equivalent effect when the information is presented in a list-based message (i.e., are narratives uniquely suited to communicate certain types of information?). We also explore the influence of distinct founder values as motives (self-enhancement and self-transcendence), introduce narrative fidelity as a mechanism in narrative persuasion, and examine brand authenticity as an outcome of increasing importance to marketers.

\section{Brand Authenticity}

Cohn and Wolfe (2014) found $87 \%$ of consumers felt it was important for brands to act with authenticity, ranking it above innovation $(72 \%)$, and product uniqueness $(71 \%)$ when asked what they valued most in a brand. Consumer perceptions of brand authenticity have been linked to attitudes (Bruhn et al., 2012; Gillmore \& Pine, 2007; Moulard et al., 2014), purchase intent (Morhart et al., 2015), and beliefs that a company is trustworthy and honest (Arnould \& Price, 2000). From a brand strategy perspective, authenticity is a core component of successful brands because it is part of a unique brand identity (Aaker, 1997). Brand managers enhance authenticity through promotions that imbue the product with values that differentiate it from other brands (Beverland, 2010).

The concept of brand authenticity is complex and multi-faceted, but it has generally been examined in marketing as a perceived attribute of a brand (Holt, 2002). Authenticity is an assessment regarding a consumer's perception of a brand's "truth," or "genuineness," rather than objective factuality (Grayson \& Martinec, 2004) and reflects a consumer's perception of whether the brand acts consistently with its essential core (Gilmore \& Pine, 2007) rather than be factually accurate (Bruhn et al., 2012). Inauthentic brands are viewed as contextually dependent and motivated by situational incentives; that is, inconsistency between what the brand is and what the brand "says" it is (Beverland \& Farrelly, 2010).

Although authenticity can be applied as agnostic to valence, our conceptualization of the construct aligns with the advertising and marketing practice in which authenticity is a desirable attribute (Morhart et al., 2015). In the context of branding, authenticity may be instantiated in terms of consistency across a range of dimensions, but they all share an element or association that is positively-evaluated or desirable to the target market. For example, some authentic 
This is an author-produced, peer-reviewed version of this article. The final, definitive version of this document can be found online at Psychology \& Marketing, published by Wiley Periodicals, Inc.. Copyright restrictions may apply. doi: 10.1002/mar.21252

brands may exhibit consistency in their style and aesthetics through uniformity of design and sensory elements, as exemplified by Apple's consistently sleek, cool, functional, user-friendly design (Spiggle, Nguyen, \& Carabella, 2012). Other brands may emphasize consistency with their heritage, such as wine makers who continue to reinforce connections with aristocratic roots. We define brand authenticity perceptions as a judgment that observable characteristics or actions associated with the brand are consistent with the brand's (brand owners') identity and "true self." For example, the offbeat design and product names of Ben and Jerry's ice cream are consistent with the quirky identity of Ben and Jerry's, the company. We return to this discussion subsequently, but next describe a process through which brand authenticity judgments can be made.

\section{$\underline{\text { Narrative Fidelity }}$}

Fisher (1984) introduced a theory of communication in which he distinguished between the rational world, where human decisions are informed by argument, fact, and logical reasoning processes, and the narrative world, in which humans are influenced by stories that present "good reasons" that conform to their understanding of history, culture, and character. Fisher's perspective is part of a broader research focus that challenged models of information processing in which humans' cognitive processes were likened to those of a computer. This literature stream illustrates how narrative thinking incorporates the construction of meaning and cultural understanding, in contrast to reductionist models of information processing (Bruner, 1990). Narratives function as a fundamental intellectual device for organizing disconnected, fragmentary events into an intelligible whole (Sarbin, 1986). People use their internal stories to judge and accept the stories that they encounter in the world outside (Polkinghorne, 1988).

Fisher termed this judgment narrative fidelity and described the process in terms of "the degree to which the story accords with the logic of good reasons" and reflects internalized standards of how people ought to act (Fisher, 1987, p. 376). This judgment is based on the reader's assessment of how the narrative coheres with her view of the world rather than the rational world paradigm, which emphasizes decontextualized fact and logic. The context provided by a narrative evokes a judgment of fidelity to assess the meaning of a character's values-in-action.

Fisher's standards for judging good reasons are grounded in values that contribute to positive consequences for the actor and, in the long run, for society (Fisher, 1984). According to Fisher, readers determine whether a narrative has fidelity by considering consequences that would occur from people adhering to the values espoused in the narrative, whether the narrative's values are consistent with what one believes, and whether the character's motivations reflect important values.

Judgments of narrative fidelity have consequences for the reader's beliefs. As Griffin (2009, p. 304) describes, "when we decide a story has fidelity we are not just affirming our shared beliefs but opening ourselves up to the thought that these values will ultimately influence our beliefs." The process of evaluating narrative fidelity links an understanding and evaluation of characters' actions with a disposition to accept the narrative implications as valid. We adapt Fisher's conceptualization of narrative fidelity to the context of a character's motivation to act and use it to help explain how values in founder's stories differ in their influence on brand authenticity.

Narrative fidelity has similarities with other processes examined in narrative persuasion research which focus on how aspects of characters in a narrative influence beliefs, such as identification with a character (Paharia et al., 2010) and character liking (Robinson \& Knobloch-Westerwick, 2017). Character identification and liking emphasize connecting to the perceiver's identity ("I felt as though I was one of the characters; I liked that character") while fidelity emphasizes the extent to which the perceiver views something as what it ought to be ("The character's actions were consistent with how people should act"). Judgments of fidelity are influenced by adherence to standards and good reasons to act. Identification and liking focus on connections to the reader, with little attention to values that underlie character actions.

\section{Development of Hypotheses}

As described previously, founder's stories reveal a character's values as motives for creating a business. Schwartz (1994) described values as lasting beliefs shared by members of a culture about what is desirable and undesirable, and which guide individuals' actions. Two opposing values identified by Schwarz (1994) - self-transcendence and selfenhancement - are prevalent from a business-creation perspective. Self-transcendence is conceptualized as concern with the well-being of others, and self-enhancement is the pursuit of personal status and success (Schwartz, 1994). For example, self-enhancement motives are evident in Milton Friedman's description of profit-motive and generation 
This is an author-produced, peer-reviewed version of this article. The final, definitive version of this document can be found online at Psychology \& Marketing, published by Wiley Periodicals, Inc.. Copyright restrictions may apply. doi: 10.1002/mar.21252

of shareholder value as the primary purpose of business and the goals of the market orientation concept (Kohli \& Jaworski, 1990). In contrast, the recent growth of social entrepreneurship highlights business as a platform to create social value and to benefit others (Dees, 1998). Studies that examine entrepreneurs' motives to create a business highlight each orientation: the desire to exploit a market opportunity and make money (Watson, Hogarth-Scott, \& Wilson, 1998) or to serve the wellbeing of a community (Miller et al., 2012). We examine whether these values influence brand authenticity distinctly.

Recent research in a parallel literature on authenticity - authentic leadership - provides insights into the relationship between founder's values and brand authenticity. Both self-transcendence and self-enhancement values are prevalent in the leadership context. Michie and Gooty (2005) demonstrate that leaders perceived as authentic give priority to self-transcendence values. Other authors (Avolio \& Gardner, 2005; Guilien et al., 2016) identify espousing and acting consistently with other-oriented (self-transcendence) values as a characteristic of authentic leaders: that is, they strive to do what is right and fair for all stakeholders and sacrifice self-interests for the collective good of their work unit, organization, community, or entire society (Avolio \& Gardner, 2005).

We propose a company founder's values embedded in a brand narrative may exert similar influence on brand authenticity: though self-transcendence and self-enhancement values may each be plausible reasons for action, selftranscendence values will have a stronger influence to enhance brand authenticity:

H1: Narratives that present founder's actions as motivated by self-transcendence values lead to higher perceptions of brand authenticity than stories which present a founder's actions as motivated by self-enhancement values.

Readers make judgments of narrative fidelity by comparing the values motivating a character's action and values that lead to positive consequences for the actor and, in the long run, for society (Fisher, 1984). Several researchers (e.g., Schultz \& Zelezny, 1999; Schwartz, 2005) have identified self-transcendence values (e.g., benevolence, universalism) as most desirable for the individual and society. These values provide a reference point (standard) to judge whether an action is based on "good reasons."

The opportunity to view values in action, as described in a founder's narrative, provides the reader with a context to judge fidelity based on whether the founder motives and actions align with a self-transcendence standard. A character whose action align with self-transcendence values demonstrates little deviation from a desirable standard to act. In contrast, a character whose actions align with self-enhancement values differ from these desirable standards. The more a character acts based on self-transcendence values, the more the actions in the narrative are perceived to be based on good reasons; that is, higher in narrative fidelity.

The reader can use this overall judgment of whether the founder acted for "good reasons" to assess whether the entity (a brand or leader) acts consistently with its desirable, and essential, core; that is, does assessment of narrative fidelity (i.e., are founder's actions based on "good reasons"?) affect the reader's perception of the brand's authenticity? For example, an observer's judgment that a leader's actions are based on "good reasons" enhances perceived authenticity of the leader. In the context of brand stories, companies founded for good reasons (i.e., higher perceived fidelity) are likely to enhance brand authenticity. In summary, we propose the values presented in a founder's narrative influence reader's judgment of narrative fidelity; that is, whether the character acted for "good reasons." This judgment, in turn, influences whether the brand is perceived to be consistent with its "true" self (authenticity). We propose:

H2: Narrative fidelity mediates the influence of founder's values on brand authenticity.

Grayson and Martinec (2004) point out that a consumer's background and beliefs will affect authenticity judgments. Similarly, perception of what constitutes "good reasons" (desirable values) can vary across individuals. For example, the endorsement of specific values can vary at a cultural (American veneration for the underdog narrative; Paharia et al., 2010) or an individual level (value of the environment; Fraj \& Martinez, 2006).

Although self-transcendence values are recognized as most important in Western culture (Schultz \& Zelezny, 1999; Schwartz, 2005), individuals will vary in their endorsement of self-transcendence values as desirable values (consistent with the way people ought to act). Individuals who view self-transcendence values as a basis for their own 
This is an author-produced, peer-reviewed version of this article. The final, definitive version of this document can be found online at Psychology \& Marketing, published by Wiley Periodicals, Inc.. Copyright restrictions may apply. doi: 10.1002/mar.21252

actions are more likely to view a business founder motivated by self-transcendence values as acting based on good reasons; that is, a reader's personal endorsement of self-transcendence values will moderate the relationship between founder's values and narrative fidelity:

H3: The reader's personal self-transcendence values moderate the relationship between values in the founder's narrative and narrative fidelity: the influence of the founder's self-transcendence values on narrative fidelity is stronger when the reader more strongly endorses self-transcendence values.

We propose narrative fidelity affects perceptions of brand authenticity because the values that motivated a founder's reasons for acting become associated with the brand. A question of conceptual and practical importance is whether this relationship is robust to changes in the relationship between the founder and the brand. Specifically, does perception of brand authenticity diminish after the founder is no longer the brand owner?

Companies often acquire brands as part of their growth strategy. The merger and acquisitions literature (Homberg \& Bucerius, 2005) suggests transfer of ownership, particularly to a larger company, raises questions about whether the brand represents what it did originally (i.e., whether the brand maintains its authenticity; Basu, 2006). This phenomenon raises a question that is relevant to the current work: namely, how does a founder's narrative influence the authenticity of the brand after it is acquired by another business? We predict that transfer of ownership from the original founder will attenuate the relationship between narrative fidelity and brand authenticity because consumers may perceive that the founder's original values may no longer characterize the contemporary brand. Formally:

H4: The relationship between narrative fidelity and authenticity is attenuated when the brand is acquired by another company.

Place Figure 1 about here

\section{Overview of Studies}

We first conducted a pilot study to examine the prevalence of self-enhancement and self-transcendence values in actual brand stories (Pilot A). In study 1, we show that narrative fidelity mediates the relationship between founder's values and brand authenticity, and that the examined relationships are stronger in a narrative (versus list-based) message. In study 2, we demonstrate that readers' self-transcendence values moderate the influence of founder's values on narrative fidelity. In study 3 , we show the relationship between narrative fidelity and brand authenticity is attenuated when another company acquires the brand, demonstrating a boundary condition of the observed relationships.

\section{Pilot Study A: Prevalence of Values}

The purpose of this pilot study was to examine the prevalence of specific values cited as founder's motives in their stories. The first author randomly selected consumer-oriented companies from the Forbes 1000 that operated in the financial or food-related sectors, which were chosen because of their direct relevance to consumers. The website of each selected company was searched for a founder's narrative. This process proceeded until 35 stories were obtained. Two trained coders, blind to hypotheses, were told their task was to read each narrative and determine the values underlying the business formation (the founder's "motive"). The coders were given Schwartz's (1994) definitions of self-transcendence ("motivated by universalism (seeking social justice and tolerance for all and benevolence (giving to others, seeking to help and provide general welfare)") and self-enhancement ("motivated by power (seeking social status and prestige) and achievement (setting hard-to-attain goals and achieving them)"). The first author and the coders independently reviewed five narratives to identify and resolve areas of ambiguity and inconsistency in the coding. The coders then read each narrative and assigned the code corresponding to the values underlying business' formation motive; disagreements were resolved through discussion. Results indicated that values do serve as motives for business formation, and self-transcendence and self-enhancement values are prevalent. See table 1 for coded responses. 
This is an author-produced, peer-reviewed version of this article. The final, definitive version of this document can be found online at Psychology \& Marketing, published by Wiley Periodicals, Inc.. Copyright restrictions may apply. doi: 10.1002/mar.21252

Place Table 1 about here

\section{Study 1: Message Format and Founder Values}

Study 1 was conducted to evaluate the hypothesis that a narrative-based message depicting a founder motivated by self-transcendence (versus self-enhancement) values enhances brand authenticity more than a list-based message. We expect narrative fidelity to mediate this relationship. We manipulated message format to determine whether presentation style affected judgments of fidelity and authenticity, based on past research which has shown that message format evokes differences in processing (Escalas, 2007).

\section{Method}

We developed a narrative and list-based version of a founder's narrative. The message described the founding of a restaurant, which allowed us to present either self-enhancement or self-transcendence values (see online appendix 3). MTurk participants $\left(\mathrm{N}=153,51 \%\right.$ male, $\left.\mathrm{M}_{\mathrm{age}}=37.95\right)$ were assigned to a condition in a 2 (message format: narrative, list-based) $\mathrm{x}$ (values: self-transcendence, self-enhancement) design. After reading the message, participants were presented with the short form of the narrative transportation scale (Appel et al., 2015; $\alpha=.79$ ), the narrative fidelity measure ( $\alpha=.95$; see online appendix 1 and 2 for scale development procedures and study 3 for measures) and the brand authenticity measure $(\alpha=.90)$.

Finally, participants completed manipulation check measures regarding the character's motivation (self-transcendence versus self enhancement) and perception of the message format.

\section{$\underline{\text { Results }}$}

Narrative Fidelity and Authenticity: Discriminant Validity. We conducted a CFA with multiple indicators of narrative fidelity and authenticity. The CFA provided a good fit $\left(\chi^{2}(26)=69.37, p=.00\right.$; CFI $=.97$; RMSEA $=.10$; Pclose $=.01)$, and the AVE values for narrative fidelity (.78) and authenticity (.76) were greater than the shared variance between the two (.56), providing evidence of their discriminant validity (Farrell, 2010). The two-factor model fit significantly better than a single factor model $\left(\chi^{2}(27)=253.89, p=.00\right)$.

Manipulation Checks. We examined whether participants perceived values exemplified by the founder as intended. We conducted a 2 (message format: narrative, list-based) x 2 (embedded values: self enhancement, self-transcendence) x 2 (dependent measure: self-transcendence, self-enhancement) mixed mode ANOVA with the two manipulation check measures as repeated measures. An interaction between measure and values emerged $(F(1,148)=150.55, p<$ .001): participants in the self-transcendence conditions were more likely to agree that the founder was motivated by benevolence and universalism $(\mathrm{M}=6.07, \mathrm{SD}=1.15)$ than participants in the self-enhancement conditions $(\mathrm{M}=2.85$, $\mathrm{M}=1.96$ ); participants in the self-enhancement conditions were more likely to agree that the founder was motivated by achievement and power $(\mathrm{M}=6.05, \mathrm{SD}=1.40)$ than participants in the self-transcendence conditions $(\mathrm{M}=3.44$, $\mathrm{SD}=1.94)$, consistent with our intended manipulation. No other effects were significant.

Participants in the narrative condition were significantly more likely to indicate the message read like a narrative than participants in the list-based condition $\left(F(1,149)=23.86, p<.001 ; \mathrm{M}_{\text {narrative }}=6.06, \mathrm{SD}=1.09 ; \mathrm{M}_{\text {list-based }}=4.84, \mathrm{SD}=\right.$ 1.77). No other effects were significant, providing support for our format manipulation.

Narrative Fidelity. A 2 (condition: narrative, list-based) x 2 (values: self-enhancement, self-transcendence) ANOVA predicting narrative fidelity yielded a main effect of values: self-transcendence values evoked more narrative fidelity than self-enhancement values $\left(F(1,149)=102.96, p<.001 ; \mathrm{M}_{\text {self-transcendence }}=5.66, \mathrm{SD}=.57 ; \mathrm{M}_{\text {self-enhancement }}=4.31\right.$, $\mathrm{SD}=1.04)$. This main effect was qualified by an interaction $(F(1,149)=13.76, p<.001)$. Participants who read the narrative containing self-enhancement values perceived less narrative fidelity than participants who read the list-based message containing these values $\left(F(1,149)=11.31, p<.001 ; \mathrm{M}_{\text {narrative }}=3.98, \mathrm{SD}=1.06 ; \mathrm{M}_{\text {list-based }}=4.59, \mathrm{SD}=.95\right)$. 
This is an author-produced, peer-reviewed version of this article. The final, definitive version of this document can be found online at Psychology \& Marketing, published by Wiley Periodicals, Inc.. Copyright restrictions may apply. doi: 10.1002/mar.21252

Participants who read the narrative presenting self-transcendence values perceived more narrative fidelity than participants who read the list-based condition containing these values $\left(F(1,149)=3.77, p=.05 ; \mathrm{M}_{\text {narrative }}=5.82\right.$, SD $=.56 ; \mathrm{M}_{\text {list-based }}=5.44, \mathrm{SD}=.58$ ). See figure 2 .

Place Figure 2 about here

Brand Authenticity. We repeated the 2 (condition: narrative, list-based) x 2 (values: self-enhancement, selftranscendence) ANOVA with brand authenticity as a dependent variable. This analysis again yielded a main effect of values: self-transcendence values evoked more authenticity than self-enhancement values $(F(1,149)=13.65, p<.001$; $\left.\mathrm{M}_{\text {self-transcendence }}=5.54, \mathrm{SD}=1.13 ; \mathrm{M}_{\text {self-enhancement }}=4.78, \mathrm{SD}=1.37\right)$. This main effect was qualified by an interaction $(F(1,149)=8.91, p=.003)$. Participants who read the narrative containing self-enhancement values perceived marginally less authenticity than participants who read the list-based message containing these values $(F(1,149)=$ $3.29, p=.06 ; \mathrm{M}_{\text {narrative }}=4.50, \mathrm{SD}=1.49 ; \mathrm{M}_{\text {list-based }}=5.00, \mathrm{SD}=1.23$ ). Participants who read the narrative presenting self-transcendence values perceived more authenticity than participants who read the list-based condition containing these values $\left(F(1,149)=5.47, p=.02 ; \mathrm{M}_{\text {narrative }}=5.84, \mathrm{SD}=.83 ; \mathrm{M}_{\text {list-based }}=5.15, \mathrm{SD}=1.34\right)$. See figure 3 .

Place Figure 3 about here

Narrative Fidelity as a Mediator of the Values-Authenticity Relationship. We conducted a moderated mediation analysis using PROCESS model 8 (Hayes, 2013): founder's values predicted fidelity, and message format moderated this relationship; narrative fidelity predicted brand authenticity (see table 2). We also entered narrative transportation as an alternative mediator (i.e., founder's values predicted transportation, and format moderated this relationship; transportation predicted brand authenticity).

We first examined narrative fidelity as a mediator. Character values influenced narrative fidelity significantly, which in turn influenced authenticity. Results indicated narrative fidelity fully mediated the relationship between the values and authenticity $(\beta=.60, \mathrm{SE}=.20,95 \% \mathrm{CI}: .25,1.07)$. Moreover, message format moderated this mediated relationship between values and authenticity: when the message was presented in a list-based format, the influence was significant $(\beta=.52, \mathrm{SE}=.1395 \% \mathrm{CI}: .31, .82)$; when the message was presented in a narrative format the influence was significantly stronger $(\beta=1.11, \mathrm{SE}=.23,95 \% \mathrm{CI}$. $.70,1.60)$.

We then examined transportation as a mediator. The influence of the format manipulation was significant: the narrative evoked higher transportation than the list-based message, as would be expected (see table 2). Moreover, transportation enhanced brand authenticity, which is also consistent with past work suggesting that immersion into a narrative enhances evaluation of a narrative-related target. Transportation did not mediate the message format authenticity relationship. We consider this finding in the discussion.

Place Table 2 about here

\section{Discussion}

Study 1 examined whether message format and values-based reasons to act influence brand authenticity. Stories about characters whose self-transcendence values motivated them to create a brand, which are viewed as "good reasons" to act, evoked stronger perceptions of brand authenticity than stories about founders motivated by self-enhancement 
This is an author-produced, peer-reviewed version of this article. The final, definitive version of this document can be found online at Psychology \& Marketing, published by Wiley Periodicals, Inc.. Copyright restrictions may apply. doi: 10.1002/mar.21252

values (supporting H1). Study 1 demonstrates that a judgment of narrative fidelity mediated the relationship between value-based reasons and authenticity. Founders motivated by self-transcendence were judged to act for "good reasons," which then affected perceived brand authenticity (supporting $\mathrm{H} 2$ ).

We found a direct effect of values on narrative fidelity, and the subsequent indirect effect on authenticity was stronger for a narrative than a list-based message, although the relationship between values and narrative fidelity remained positive in the list-based condition. This positive relationship between values - narrative fidelity for the list-based message may reflect the mere presence of values in a message will evoke some perceived narrative fidelity; that is, the values "ring true" in the context of information about what motivated a founder to create a company. This effect of values on judgments of narrative fidelity, however, is more pronounced in a narrative format. Finally, consistent with past research, narrative format enhanced transportation, which subsequently increased brand authenticity. However, transportation did not mediate the influence of values on authenticity ${ }^{1}$.

\section{Study 2: The Role of Readers' Values}

Study 2 builds on study 1 in two ways. First, it is a replication of study 1 in a different business context to evaluate whether study 1's results generalize to other domains; that is, whether people continue to view a narrative in which a founder is motivated by self-transcendence values as higher in fidelity than a founder motivated by self-enhancement values. We expect that the reader's personal values will moderate the relationship between founder's values and readers' judgments of narrative fidelity because fidelity judgments are the result of a comparison process between the values in the narrative and one's values (H3). Study 2 will assess how reader's values moderates the effects demonstrated in study 1 and provide evidence of narrative fidelity's construct validity.

\section{Method}

MTurk participants $\left(\mathrm{N}=133,55.6 \%\right.$ male, $\left.\mathrm{M}_{\text {age }}=33.6\right)$ were randomly assigned to read one of two stories about the founding of a private school: a self-transcendence narrative or a self-enhancement narrative (see online appendix 4). We selected an education context because it is a context with which most people are familiar, where choices are determined in part by values (Bosetti, 2004), and is a large and growing sector in the U.S. and internationally (Zion Market Research, 2018). After reading the narrative, participants were presented with the narrative fidelity measure $(\alpha=.97)$, the authenticity measure $(\alpha=.92)$, and the four self-transcendence items from the Personal Values Questionnaire (Schwartz et al., 2012; $\alpha=.78$ ). The PVQ includes short verbal portraits of different people that describe a person's goals or aspirations that point to the importance of a basic value.

\section{$\underline{\text { Results }}$}

Narrative Fidelity and Authenticity: Discriminant Validity. A CFA with multiple indicators of narrative fidelity and authenticity provided a good fit $\left(\chi^{2}(26)=32.77, p=.17\right.$; CFI $=1.00 ;$ RMSEA $=.04 ;$ Pclose $\left.=.71\right)$, and the AVE values for narrative fidelity $(.84)$ and authenticity $(.81)$ were greater than the shared variance between the two $(.80)$, providing evidence of their discriminant validity (Farrell, 2010).

Founder's Values, Narrative Fidelity, and Brand Authenticity. A one-way ANOVA indicated founder's values evoked different levels of narrative fidelity $\left(F(1,131)=51.71, p<.001 ; \mathrm{M}_{\text {self-transcendence }}=5.95, \mathrm{SD}=.95 ; \mathrm{M}_{\text {self-enhancement }}\right.$ $=4.65, \mathrm{SD}=1.52)$ and brand authenticity $\left(F(1,131)=18.83, p<.001 ; \mathrm{M}_{\text {self-transcendence }}=5.64, \mathrm{SD}=1.06 ; \mathrm{M}_{\text {self-enhancement }}\right.$ $=4.48, \mathrm{SD}=1.36$ ).

Founder's Values, Reader Self-Transcendence Values, and Narrative Fidelity. We used a regression-based approach to examine the influence of founder's values $(0=$ self-enhancement, $1=$ self-transcendence $)$ on narrative fidelity and whether readers' self-transcendence values moderated the relationship of founder's values and narrative fidelity. The direct effect of founder's values on narrative fidelity was significant: a founder motivated by selftranscendence values evoked higher levels of narrative fidelity (see table 3), qualified by an interaction between founder's values and reader's self-transcendence values. At 1 SD below the reader mean of self-transcendence, founder's values of self-transcendence values were marginally related to narrative fidelity $(\beta=.53, \mathrm{t}=1.94, p=.055)$. At 1 SD above the reader's mean of self-transcendence, the relationship between founder's self-transcendence values and fidelity was significantly stronger $(\beta=2.31, \mathrm{t}=8.37, p<.001)$. See figure 4 . 
This is an author-produced, peer-reviewed version of this article. The final, definitive version of this document can be found online at Psychology \& Marketing, published by Wiley Periodicals, Inc.. Copyright restrictions may apply. doi: 10.1002/mar.21252

Narrative Fidelity and Authenticity. We regressed authenticity onto narrative fidelity and the founder's values narrative condition. Narrative fidelity was a significant predictor (see table 3). We conducted additional analyses in which reader values and their interaction with narrative condition were entered as predictors. Neither the direct effect nor interactions were significant.

Moderated Mediation: Readers' Self-Transcendence Values. We used PROCESS (model 8; Hayes, 2013) to examine narrative fidelity as a mediator of the relationship between founder's values and brand authenticity, with readers' self-transcendence values as a moderator of the founder's values - narrative fidelity relationship. Narrative fidelity fully mediated the values -authenticity relationship $(\beta=1.10, \mathrm{se}=.20,95 \% \mathrm{CI}=.76,1.54)$. The indirect effect was significant at low ( $1 \mathrm{SD}$ below the mean: $\beta=.40, \mathrm{SE}=.18,95 \% \mathrm{CI}: .06, .78)$ and high (1 SD above the mean: $\beta$ $=1.74, \mathrm{SE}=.32,95 \% \mathrm{CI}: 1.15,2.42$ ) levels of readers' self-transcendence values, but it was significantly stronger at higher levels, as indicated by the index of moderated mediation $(\beta=.94, \mathrm{SE}=.26,95 \% \mathrm{CI}$ : .49, 1.51).

Place Table 3 and Figure 4 about here

\section{$\underline{\text { Discussion }}$}

Study 2 replicates the findings of study 1 : stories about characters whose self-transcendence values motivated them to create a brand evoked stronger perceptions of brand authenticity than stories about founders motivated by selfenhancement values (supporting H1), and this relationship was mediated by narrative fidelity (supporting H2).

Readers' narrative judgments are affected by their background, and two readers of the same narrative may differ in their assessments of a narrative's fidelity and its subsequent effect on brand and product perceptions. Although selftranscendence values were perceived by consumers on average as "better reasons" to act than self-enhancement values, we found that readers' personal values affected the relationship between founder's values and narrative fidelity: readers higher in self-transcendence values viewed the relationship between self-transcendence founder's values and narrative fidelity more positively than readers lower in self-transcendence values (supporting H3). Broadly, these findings demonstrate that the founder's values affect narrative fidelity (i.e., self-transcendence values provide a better reason to act than self-enhancement values), and that readers' values can enhance or diminish that relationship, providing evidence for the construct validity of narrative fidelity. One potential limitation of the current study is that processing fluency may serve as a plausible alterative explanation: past work suggests individuals may process messages consistent with their worldview more easily and lead them to respond more favorably to the message target (Lee \& Aaker, 2004). We collected additional data which does not support this explanation ${ }^{2}$. In the next study, we examine a context in which we attenuate the influence of narrative fidelity on brand authenticity.

\section{Study 3: Attenuating the Relationship Between Narrative Fidelity and Authenticity}

Study 3 uses a merger and acquisition context to examine a condition under which the relationship between fidelity and authenticity may be attenuated. We show that the acquisition of a brand by a large company reduces the authenticity associated with the original company, which also provides substantive insights for brand managers.

\section{Method}

We adapted a founder's narrative about the creation of a dairy (see online appendix 5). One version described a commitment to self-transcendence values while the other described a commitment to self-enhancement values. MTurk participants $\left(\mathrm{N}=155, \mathrm{M}_{\mathrm{age}}=35.3 ; 45.2 \%\right.$ female $)$ read one narrative and then responded to the narrative fidelity $(\alpha=$ .95) scale. Some participants were then presented with a mock press release describing the sale of the dairy to Nestlé, resulting in a 2 (founder's values: self-transcendence, self-enhancement) x 2 (business acquisition: present, absent) between-subjects design. Participants were then presented with the authenticity measures used in prior studies $(\alpha=$ $.97)^{3}$, an attention check, and a manipulation check measure of perceived values in the narrative (see online appendix for measures). 
This is an author-produced, peer-reviewed version of this article. The final, definitive version of this document can be found online at Psychology \& Marketing, published by Wiley Periodicals, Inc.. Copyright restrictions may apply. doi: 10.1002/mar.21252

\section{$\underline{\text { Results }}$}

Attention and Manipulation Check. Most participants (93.5\%) correctly identified the values embedded in the stories (analyses that included and excluded those who did not correctly identify the values did not differ; we included all respondents in the analyses). Participants in the self-transcendence condition were more likely to perceive selftranscendence values motivating the founder than participants in the self-enhancement condition $(t(153)=6.67, p<$ $\left..001 ; \mathrm{M}_{\text {self-transcendence }}=5.52, \mathrm{SD}=1.53 ; \mathrm{M}_{\text {self-enhancement }}=3.49, \mathrm{SD}=2.04\right)$. Conversely, participants in the selfenhancement condition were more likely to perceive self-enhancement values motivating the founder than participants in the self-transcendence condition $\left(t(153)=153, p<.001 ; \mathrm{M}_{\text {self-enhancement }}=5.87, \mathrm{SD}=1.60 ; \mathrm{M}_{\text {self-transcedence }}=3.91, \mathrm{SD}\right.$ $=1.83$ ).

Narrative Fidelity. We conducted a one-way ANOVA to compare the influence of the narrative condition on narrative fidelity. As expected, participants who read the self-transcendence narrative perceived more narrative fidelity than participants who read the self-enhancement narrative $\left(F(1,153)=18.75, p<.001 ; \mathrm{M}_{\text {self-transcendence }}=5.60, \mathrm{SE}=.97\right.$; $\left.\mathrm{M}_{\text {self-enhancement }}=4.75, \mathrm{SD}=1.44\right)$.

Narrative Authenticity. We conducted a 2 (narrative values) x 2 (press release) ANOVA on authenticity. The main effects of founder values $(F(1,151)=4.29, \mathrm{p}=.04)$ and press release condition $(F(1,151)=34.67, p<.001)$ were significant, and were qualified by an interaction $(F(1,151)=5.31, p=.02)$. Participants who read the selftranscendence narrative perceived the brand as less authentic when accompanied by a press release $(F(1,151)=34.23$, $\left.p<.001 ; \mathrm{M}_{\text {press release }}=4.23, \mathrm{SD}=1.60 ; \mathrm{M}_{\text {no press release }}=6.15, \mathrm{SD}=1.84\right)$. Participants who read the self-enhancement nafrrative also perceived the brand as less authentic when accompanied by a press release $(F(1,151)=6.30, p=.01$; $\mathrm{M}_{\text {press release }}=4.29, \mathrm{SD}=1.85 ; \mathrm{M}_{\text {no press release }}=5.13, \mathrm{SD}=1.38$ ). See figure 5 .

Place Figure 5 about here

Narrative Fidelity - Authenticity Relationship Moderated by Business Acquisition: We used regression to examine whether the business acquisition moderated the relationship between narrative fidelity and authenticity. Business acquisition $(\beta=-1.35, t=-6.55, p<.001)$ and narrative fidelity $(\beta=.60, t=7.50, p<.001)$ were related to authenticity. Their interaction was also significant $(B=-1.35, t=-2.19, p=.03)$; when the business was not acquired by another company, narrative fidelity had a positive influence on authenticity $(\beta=.76, t=6.72, p<.001)$. When the business was acquired by another company, the influence of fidelity on authenticity was significant but diminished in magnitude ( $B=.42, t=3.82, p<.001)$, supporting $\mathrm{H} 4$.

Moderated Mediation. We used PROCESS (model 14, Hayes, 2013) to examine the indirect influence of the values manipulation on brand authenticity when the company was (or was not) sold. Mediation analyses indicated that, when a press release about the acquisition was not presented to participants, narrative fidelity mediated the relationship between the influence of founder's values on authenticity $(B=.67, \mathrm{SE}=.18,95 \% \mathrm{CI}$ : $.35,1.07)$. When participants were presented with the press release indicating the company had been acquired, narrative fidelity mediated the founder's values - authenticity relationship ( $\beta=.37, \mathrm{SE}=.15,95 \% \mathrm{CI}$. .10, .69), but the index of moderated mediation indicated the indirect effects differed significantly between the two business acquisition conditions $(\beta=-.31, \mathrm{SE}=$ $.18,95 \%$ CI: $-.75,-.04)$.

\section{$\underline{\text { Discussion }}$}

Study 3 demonstrates a condition under which the relationship between narrative fidelity and brand authenticity is attenuated, supporting hypothesis 4 . As suggested by past work (Homburg \& Bucerius, 2005), consumers may be uncertain as to whether the acquiring company will maintain the same values that were established at the company's founding. Our findings suggest consumers can update assessments of a brand's authenticity given evidence that the "brand truth" suggested in a related narrative may no longer be relevant. The finding that self-enhancement evoked perceived higher authenticity when the business had not been sold suggests the mere presence of values may enhance perceived authenticity; when a business is sold to a large company, readers are less likely to view the brand as true to its original identity. 
This is an author-produced, peer-reviewed version of this article. The final, definitive version of this document can be found online at Psychology \& Marketing, published by Wiley Periodicals, Inc.. Copyright restrictions may apply. doi: 10.1002/mar.21252

An alternative account of our results is that consumers may infer that a founder's decision to sell the business reveals a motive to make money, which contrasts with motives articulated by a founder in the self-transcendence condition. The decision to sell may thus be perceived as inauthentic in itself. We further consider this possibility in the limitations and future directions section.

\section{General Discussion}

Founder's stories can reflect values and ideologies (Holt, 2002) that influence consumer perception of and response to brands. The current work shows that founders, when motivated by self-transcendence values, evoke higher narrative fidelity judgments (i.e., the founder is acting based on "good reasons"), which subsequently enhance brand authenticity. The influence of founders' values on narrative fidelity is enhanced when the reader endorses selftranscendence values, and the relationship between narrative fidelity and authenticity is attenuated when a brand is acquired by a large company. The current work has theoretical implications for research on narrative persuasion and brand authenticity.

\section{Theoretical Contributions}

Narrative Persuasion and Narrative Fidelity. The term narrative persuasion was developed to describe the influence of narrative-based messages on persuasion-related outcomes, which occur via mechanisms not considered by traditional models of argument-based persuasion (Escalas, 2004). Bruner (1986, p. 11), for example, noted that people assess rhetorical communication expressions in terms of objective factuality and stories in terms of their "lifelikeness." The current work builds on this idea and highlights how a reader judges a character's actions based on whether they represent "good reasons," rather than whether they adhere to evidence-based standards of what is normative or prevalent. The current work identifies and examines the influence of an element common to stories but not examined in research on narrative persuasion: character motivations (values). Further, the current work expands the prevailing narrative persuasion model in which transportation is the sole mediator (van Laer et al., 2014) by examining narrative fidelity as a process through which the character motivations influence narrative-related beliefs. Future work can examine whether narrative fidelity and transportation interact, occur in sequence, or operate in a parallel manner. Finally, narrative persuasion research typically examines narrative-related beliefs, attitudes, and intentions. In the current work, we focus on the effect of narrative processing on a specific brand-related belief - authenticity - because of its relevance to consumer choice.

Authenticity. The study of authenticity has become important in the so-called experience economy (Gilmore \& Pine, 2007), and the consumer literature research highlights its influence on desirable consumer-related outcomes (Beverland \& Farrelly, 2010). The current work extends past research by articulating aspects of messages that enhance authenticity: specifically, values that motivate a brand's creation. Although past work has emphasized that authenticity perceptions can range widely across consumers, the current work identifies a factor - the presence of selftranscendence values - which consistently enhances authenticity judgments. Moreover, the current work draws insights from the literature on authentic leadership, bridging the two fields, and pointing to this literature as a source for additional insights.

\section{Applied Implications}

Practitioners have long recognized that sharing founder's stories promotes audience engagement, and the current work provides empirical support that these stories are an effective way to enhance authenticity judgments of a focal brand. Members of the Millennial generation are notably concerned about the authenticity of the brands they consume, and the current research is particularly timely, given the size and growing influence of this consumer segment.

First, the current work suggests that presenting a company's founding in a narrative format has a stronger influence on authenticity than a list-based message. Companies that present information about their founding by using a timeline format may be foregoing an opportunity to engage and influence potential consumers.

The current work suggests that a narrative which presents a founder as motivated by self-transcendence enhances brand authenticity more than a founder motivated by self-enhancement. Practitioners highlight how motives for a founder's actions (or other company-related character) demonstrate an interest in the welfare of others, either 
This is an author-produced, peer-reviewed version of this article. The final, definitive version of this document can be found online at Psychology \& Marketing, published by Wiley Periodicals, Inc.. Copyright restrictions may apply. doi: 10.1002/mar.21252

specifically (a named other who experienced a problem that the founder seeks to resolve) or for society in general. Understanding the values of the target market also plays a role: consumers higher in self-transcendence values are particularly more receptive to stories featuring those values.

Finally, the current work provides a note of caution for companies acquiring brands. Often the acquisition of a "grassroots" brand by a large company (such as Tom's of Maine's by Colgate-Palmolive) is done with minimal fanfare to preserve the authenticity of the original brand. The results of the current study suggest this is warranted, but also suggest another approach: acquiring companies should explicitly articulate how they will preserve the values of the original founder to stave off erosion of the perceived authenticity.

\section{$\underline{\text { Future Research }}$}

The current work examines how a facet of plot content (founders' motivating values) affects narrative fidelity, or the sense that the narrative "rings true." Elements related to narrative production and aesthetics may also influence this judgment. For example, audiences may make fidelity judgments based on stylistic elements related to background music, cinematography, or character appearance. Despite the relevance of these facets to the growing practice of video-based brand storytelling, minimal research in the consumer and related fields examines the influence of narrative production elements on audience fidelity judgments and subsequent persuasion. This represents an area that would contribute to both theory and practice.

Research that examines how merger and acquisition-related stories influence brand attitudes and judgments (such as brand authenticity) represents another valuable area of work. Consumers may respond differently to stories about mergers depending on factors such as the original company's size, industry, and owners' reasons for selling. As aforementioned, one potential interpretation of study 3 is that consumers may view a founder's articulated selftranscendence motives and decision to sell a business (i.e., revealed underlying motives to make money) as incongruous. Future research can examine this possibility by manipulating characteristics of the sellers that might influence the attributions that consumers make about factors motivating the sale. For example, consumers may view the actions of owners who are older and nearing retirement differently from younger owners who sold when offered a large sum of money.

The moderating influence of culture or other broad segmentation bases represents an important area for future research. The present research was conducted with sample of individuals residing in individualistic cultures, where there is likely more variation in the extent to which individuals endorse self-transcendence or self-enhancement values. In collectivist societies, we would expect more homogeneity across individuals in terms of their endorsement of selftranscendent values. However, one's values vary in ways beyond the self-transcendence versus enhancement distinction, such as in the extent to which one endorses conservatism versus openness-to-change (Schwartz, 1994). Individuals' endorsement of these (and other) values may be robust to the individualism-collectivism cultural distinction, but may covary with other broad cultural characteristics, such as political orientation. For example, a narrative in which the founder was motivated by a desire to preserve tradition may resonate well with a politically conservative or more religious audience.

Moreover, attempts to persuade a resistant group may be more successful when the actor's motives are consistent with the values espoused by that group. For example, a narrative promoting environmentalism may be more persuasive with conservative groups (who typically oppose environmental initiatives) when characters in the promotional message act because of a desire to preserve a traditional way of living.

Finally, future research can examine the efficacy of narrative-based corrections to misinformation (information originally presented as true and subsequently learned to be false), which increasingly presents a problem for modern society (Lewandowsky et al., 2012). For example, many people persisted in their belief that vaccines cause Autism, despite learning that the study implicating the relationship was discredited. A counter-message in narrative-format may be more effective in retracting and correcting misinformation than a decontextualized, fact-based retraction, particularly when it is high in narrative fidelity. A corrective narrative high in narrative fidelity may motivate the audience to revise their beliefs and facilitate the process through providing a concrete counter example. Overall, research incorporating narrative fidelity into a model of narrative persuasion represents important directions for application and theory development. 
This is an author-produced, peer-reviewed version of this article. The final, definitive version of this document can be found online at Psychology \& Marketing, published by Wiley Periodicals, Inc.. Copyright restrictions may apply. doi: 10.1002/mar.21252

\section{References}

Aaker, J. (1997). Dimensions of brand personality, Journal of Marketing Research, 34, 347-356.

Adaval, R., \& Wyer Jr, R. S. (1998). The role of narratives in consumer information processing. Journal of Consumer Psychology, 7(3), 207-245.

Appel, M., Gnambs, T., Richter, T. \& Green, M. (2015). The transportation scale-short form (TS-SF). Media Psychology, 18, 243-266.

Arnould, E. J. \& Price, L. (2000). Authenticating acts and authoritative performances in The why of consumption: Contemporary perspectives on consumers' motives, goals, and desires, eds. Ratneshwar, S., Mick, D. \& Huffman, C, New York: Routledge, 144-163.

Avolio, B. J., \& Gardner, W. L. (2005). Authentic leadership development: Getting to the root of positive forms of leadership, The Leadership Quarterly, 16, 315-38.

Basu, K. (2006). Merging brands after mergers, California Management Review, 48, $28-40$.

Beverland, M. B., \& Farrelly, F. (2010), The quest for authenticity in consumption: Consumers' purposive choice of authentic cues to shape experienced outcomes, Journal of Consumer Research, 36, 838-856.

Bex, F., Atkinson, K., \& Bench-Capon, T. (2014). Arguments as a new perspective on character motive in stories, Literary and Linguistic Computing, 29, 467-487.

Bosetti, L. (2004). Determinants of school choice: Understanding how parents choose elementary schools in Alberta. Journal of Education Policy, 19, 387-405.

Bower, G. H., \& Morrow, D. H. (1990). Mental models in narrative comprehension, Science, 247, 44-48.

Bruhn, M., Schoenmüller, V., \& Schäfer, D., \& Heinrich, D. (2012). Brand authenticity: Towards a deeper understanding of its conceptualization and measurement. Advances in Consumer Research, 40, 567-576.

Bruner, J. S. (1986). Actual minds, possible worlds. Cambridge, MA: Harvard University Press.

Bruner J. S. (1990). Acts of meaning. Cambridge, MA: Harvard University Press.

Carnoy, J. (2016). 7 Habits of remarkably authentic brands, entrepreneur.com. Available at https://www.entrepreneur.com/article/269659.

Churchill Jr., G. A. (1979). A paradigm for developing better measures of marketing constructs, Journal of Marketing Research, 16, 64-73.

Cohn and Wolfe (2014). Authentic brands 2014: Key findings. Available at http://www.cohnwolfe.com/en/authenticbrands/keyfindings.

Dees, J. G. (1998). Enterprising nonprofits, Harvard Business Review, 76, 54-69.

Escalas, J. E. (2004). Imagine yourself in the product: Mental simulation, narrative transportation, and persuasion, Journal of Advertising, 33, 37-48.

Escalas, J. E. (2007). Self-referencing and persuasion: Narrative transportation versus analytical elaboration. Journal of Consumer Research, 33(4), 421-429.

Farrell, A. M. (2010). Insufficient discriminant validity: A comment on Bove, Pervan, Beatty, and Shiu (2009). Journal of Business Research, 63, 324-327.

Fisher, W. R. (1984). Narration as a human communication paradigm: The case of public moral argument, Communications Monographs, 51, 1-22.

Fisher, W. R. (1987). Technical logic, rhetorical logic, and narrative rationality. Argumentation, 1, 3-21.

Fraj, E. \& Martinez, E. (2006). Environmental values and lifestyles as determining factors of ecological consumer behaviour: an empirical analysis, Journal of Consumer Marketing, 23, 133-144.

Gilmore, J. H., \& Pine, B. (2007). Authenticity: What consumers really want. Cambridge, MA: Harvard University Press.

Grayson, K. \& Martinec, R. (2004). Consumer perceptions of iconicity and indexicality and their influence on assessments of authentic market offerings, Journal of Consumer Research, 31, 296-312.

Gray, K., \& Young, L., \& Waytz, A. (2012), Mind perception is the essence of morality, Psychological Inquiry, 23, 101-124.

Griffin, E. (2009). A first look at communication theory, 7th Ed. New York: McGraw Hill.

Guillen, L., Karelaia, N., \& Leroy, H. L. (2016). The authenticity gap: When authentic individuals are not regarded as such and why it matters, INSEAD working paper no. 2016/08/DSC accessed at: https://sites.insead.edu/facultyresearch/ research/doc.cfm?did=57662.

Hayes, A. F. (2013). Introduction to mediation, moderation, and conditional process analysis: A regression-based approach, Guilford Press.

Holt, Douglas B. (2002), Why do brands cause trouble? A dialectical theory of consumer culture and branding. Journal of Consumer Research, 29, 70-90. 
This is an author-produced, peer-reviewed version of this article. The final, definitive version of this document can be found online at Psychology \& Marketing, published by Wiley Periodicals, Inc.. Copyright restrictions may apply. doi: 10.1002/mar.21252

Homburg, C \& Bucerius, M. (2005). A marketing perspective on mergers and acquisitions: How marketing integration affects postmerger performance, Journal of Marketing, 69, 98-113.

Kohli, A, \& Jaworski, B. (1990). Market orientation: the construct, research propositions, and managerial implications, The Journal of Marketing, 54, 1-18.

Lee, A. Y, \& Aaker, J. (2004). Bringing the frame into focus: the influence of regulatory fit on processing fluency and persuasion, Journal of Personality and Social Psychology, 86, 205-218.

Lewandowsky, S., Ecker, U. K., Seifert, C. M., Schwarz, N., \& Cook, J. (2012). Misinformation and its correction: Continued influence and successful debiasing. Psychological Science in the Public Interest, 13, 106-131.

Lynch J, G. (2011). Meaningless mediation, Society for Judgment and Decision Making Newsletter, 30.

Miller, T. L., Grimes, M.G., McMullen, J. S., \& Vogus, T. J. (2012), Venturing for others with heart and head: How compassion encourages social entrepreneurship, Academy of Management Review, 37, 616-640.

Michie, S., \& Gooty, K. (2005). Values, emotions, and authenticity: Will the real leader please stand up? The Leadership Quarterly, 16, 441-457.

Morhart, F., Malär, L., Guevremont, A., Girardin, F., \& Grohmann, B. (2015). Brand authenticity: An integrative framework and measurement scale, Journal of Consumer Psychology, 25, 200-218.

Moulard, J. G., Rice, D. H., Garrity, C. P., \& Mangus, S. M. (2014). Artist authenticity: How artists' passion and commitment shape consumers' perceptions and behavioral intentions across genders, Psychology \& Marketing, 31, 576-590.

Padgett, D., \& Allen, D. (1997). Communicating experiences: A narrative approach to creating service brand image, Journal of Advertising, 26, 49-62.

Paharia, N., Keinan, A., Avery, J., Schor, J. B. (2010). The underdog effect: The marketing of disadvantage and determination through brand biography, Journal of Consumer Research, 37, 775-790.

Petty, R. E., \& Cacioppo, J. T. (1986). The elaboration likelihood model of persuasion. In Communication and persuasion (pp. 1-24). Springer, New York, NY.

Polkinghorne, D. (1988). Narrative knowing and the human sciences. Albany: State University of New York Press.

Robinson, M. J. \& Knobloch-Westerwick, S. (2017). Bedtime stories that work: The effect of protagonist liking on persuasion, Health Communication, 32, 339-346.

Sarbin, T. R. (Ed ). (1986). Narrative psychology. The storied nature of human conduct. New York. Praeger.

Schultz, P. W., \& Zelezny, L. (1999). Values as predictors of environmental attitudes: Evidence for consistency across 14 countries. Journal of Environmental Psychology, 19(3), 255-265.

Schwartz, M. S. (2005). Universal moral values for corporate codes of ethics, Journal of Business Ethics, 59, $27-44$.

Schwartz, S. H. (1994). Are there universal aspects in the structure and contents of human values? Journal of Social Issues, 50, 19-45.

Schwartz, S. H., Cieciuch, J., Vecchione, M., Davidov, E., Fischer, R., Beierlein, C., \& Ramos, A. (2012). Refining the theory of basic individual values. Journal of Personality and Social Psychology, 103, 663.

Spiggle, S, Nguyen, H. T., \& Caravella, M. (2012). More than fit: brand extension authenticity. Journal of Marketing Research, 49, 967-983.

Stutts, N. B., \& Barker, R. T. (1999). The use of narrative paradigm theory in assessing audience value conflict in image advertising, Management Communication Quarterly, 13, 209-244.

van Laer, T., de Ruyter, K., Visconti, L., \& Wetzels, M. (2014). The extended transportation-imagery model: A meta-analysis of the antecedents and consequences of consumers' narrative transportation, Journal of Consumer Research, 40, 797-817.

Watson, K., Hogarth-Scott, S., \& Wilson, N. (1998). Small business start-ups: success factors and support implications, International Journal of Entrepreneurial Behavior and Research, 4, 217-238.

Zion Marketing Research (2018). U.S. education market by type; Industry analysis, size, share, growth, trends, and forecast, 2018 - 2026. Available at available at http://www.cohnwolfe.com/en/authenticbrands/keyfindings. 
This is an author-produced, peer-reviewed version of this article. The final, definitive version of this document can be found online at Psychology \& Marketing, published by Wiley Periodicals, Inc.. Copyright restrictions may apply. doi: 10.1002/mar.21252

\section{Footnotes}

${ }^{1}$ We assessed whether character identification, character liking, and social desirability were additional plausible alternative mechanisms to explain the relationship between founder's values and brand authenticity. We conducted a separate study with MTurk participants $\left(\mathrm{N}=143,48.3 \%\right.$ male, $\left.\mathrm{M}_{\mathrm{age}}=36.0\right)$ who were randomly assigned to read one of the two narrative-format stories (2-condition design). After reading the narrative, the participants were presented with the narrative fidelity measure $(\alpha=.96)$, the brand authenticity measure $(\alpha=.95)$, character identification as adapted from Paharia and colleagues (2010; 6 items, $\alpha=.96$ ), character liking ("Please consider Mark Camden and evaluate him on the following dimensions: Bad-Good; Unlikeable-Likeable; Unappealing-Appealing, 7-point scale; $\alpha$ $=.94$ ) and social desirability (Stober Social Desirability measure; 16 items, $\alpha=.76$ ). We used PROCESS (model 4; Hayes 2013) to examine our hypothesized model: fidelity mediated the relationship between founder's values and brand authenticity, controlling for character liking, identification with the brand, and social desirability $(\beta=.09, \mathrm{SE}=$ $.06,95 \% \mathrm{CI}: .01, .24)$, which indicates the role of fidelity as a mediator is not redundant with these alternative explanations and represents a distinct mechanism to describe the relationship between founder's values and brand authenticity.

${ }^{2}$ MTurk participants $\mathrm{N}=151,50.3 \%$ male, $\mathrm{M}_{\text {age }}=39.1$ completed the same study and responded to the question "How would you evaluate your experience while reading the narrative: $1=$ very difficult to process, $7=$ very easy to process; $1=$ very difficult to understand, $7=$ very easy to understand; $r=-.87, \mathrm{p}<.001$; Lee and Aaker 2004. Neither the main effect of founder's values on processing fluency nor the readers' self-transcendence or self-enhancement values moderated the founder's values - processing fluency relationship $(t$ 's $<.61, p$ 's $<.54)$.

${ }^{3}$ We also collected Bruhn et al.'s authenticity measures $(2012 ; 16$ items, $\alpha=.98)$ to evaluate convergent validity. The two authenticity measures were correlated $.85, p<.001$. In the following analyses, we report the authenticity measure used in prior studies, but the results with the alternative measure were empirically equivalent, providing evidence of convergent validity. 